\title{
CLIENTELISMO POLÍTICO EN CUETZALAN, PUEBLA
}

POLITICAL CLIENTELISM IN CUETZALAN, PUEBLA

MARÍA TERESA LOZANO O'REILLY'

RESUMEN: Debido a su alto grado de marginalidad, el municipio de Cuetzalan constituye un espacio propicio para que se presente el llamado clientelismo político. Adicionalmente, el ingreso del sistema de partidos a los espacios tradicionalmente comunitarios ha desvirtuado la idea de que merece gobernar aquella persona que ha trabajado en favor de la comunidad y constituye un ejemplo a seguir. Actualmente detentan el poder quienes han tenido acceso a recursos para repartir. Esta situación genera un compromiso moral para retribuir los beneficios recibidos, aunado al temor de perderlos. Se ha naturalizado la idea de que un buen candidato o candidata es quien tiene recursos para repartir y por lo tanto, merece gobernar. Dichas conductas constituyen violaciones a los derechos humanos por lo que es importante denunciarlas y de esta manera mandar un mensaje a la sociedad de que están prohibidas y deben ser reprobadas.

Palabras Clave: Cuetzalan, clientelismo, condicionamiento del voto, derechos político electorales, delitos electorales, programas sociales, violencia política.

ABStRACT: Due to its high degree of marginality, the municipality of Cuetzalan constitutes a space propitious for the so-called political clientelism. Additionally, the entry of the political parties to spaces that have been traditionally comunal, has distorted the idea that the person who has worked in favor of the community, and is an example to follow, is the one deserved to govern. At the present time, power has been held

${ }^{1}$ Licenciada en derecho por la Universidad Nacional Autónoma de México, en donde también cursó la maestría en derecho. Actualmente forma parte del programa de doctorado en derecho del Instituto de Investigaciones Jurídicas de la UNAM con el tema de investigación "Derechos político electorales de las mujeres indígenas del municipio de Cuetzalan del Progreso". Ha participado en diversos proyectos de investigación y docencia relacionados con el tema de derechos humanos de las mujeres. <mariterelozano@gmail.com> 
by those who have had access to resources to distribute. This situation generates in the citizens a moral commitment to repay the benefits received, coupled with the fear of losing such benefits. The idea that a good candidate is the one who has resources to distribute and therefore deserves to govern has been normalized. These conducts constitute violations of human rights, and it is important to denounce them and in this way send a message to society that they are forbidden and should be condemned.

KEYWORDS: Cuetzalan, clientelism, vote conditioning, electoral political rights, electoral crimes, social programs, political violence.

SUMARIO: I. Introducción; II. Situación marginal del municipio de Cuetzalan del Progreso; III. "El tejido comunitario se va dañando con el sistema político electoral”; VI. Cuetzalan, tierra fértil para el reparto de dádivas y programas sociales. 1. Compromiso moral. 2. Temor a perder beneficios; V. Obligación "de dar" como valor entendido; VI. "El que paga para llegar, llega para robar"; El clientelismo como violación de derechos; VII Conclusión; VIII. Fuentes.

\section{I N T RO D U C C I Ó N}

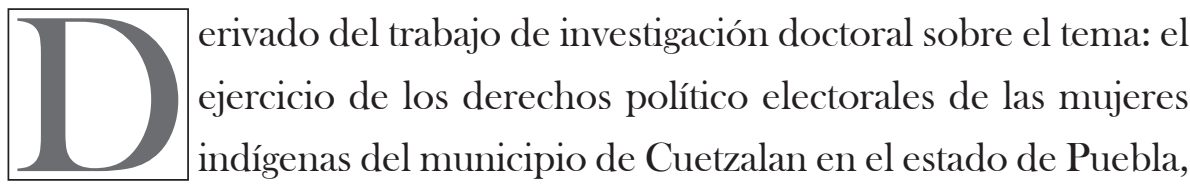
hemos ido descubriendo un fenómeno, que si bien no es completamente ajeno al tema que nos ocupa, merece la pena atenderlo por separado y dedicarle un espacio propio.

Nos referimos a la percepción de las y los gobernados de las comunidades del municipio estudiado, sobre la principal función de los gobernantes y de los parámetros con los cuales se evalúa el desempeño de las autoridades, tanto comunitarias como municipales. 
Sorprendentemente las y los gobernados ven en gobernantes, candidatas y candidatos, benefactores directos de bienes de primera necesidad. Las comunidades observadas constituyen lugares de alto grado de marginación, situación que es aprovechada por quienes detentan el poder o bien por quienes pretenden obtenerlo para manipular a la población con la entrega de "apoyos" a cambio de "votos".

Como parte del trabajo de campo desarrollado en el municipio, se han llevado a cabo varias entrevistas a profundidad con personas que hemos denominado "observadores privilegiados", es decir, personas “conocedoras expertas del fenómeno, cuya visión directa y profunda del mismo ... los sitúa en una posición de observación privilegiada”; entrevistas a profundidad a ex candidatas a la presidencia municipal en las elecciones de 2018; distintas observaciones, incluida la llevada a cabo el día de la jornada electoral del 1 de julio de 2018 y el día de la elección extraordinaria del 2 de junio de 2019; aplicación de encuestas a mujeres de la comunidad, tanto el día de la elección afuera de las casillas seleccionadas para la observación, como unos meses después en cuatro comunidades del municipio, así como conversaciones aleatorias y casuales con hombres y mujeres del municipio en espacios públicos como plazas, mercados y comercios.

Derivado del trabajo de campo, hemos recopilado testimonios de diferentes actores, principalmente mujeres, que nos refieren la manipulación de que tradicionalmente ha sido objeto la población por medio del reparto de programas sociales y demás beneficios, lo que genera, por una parte el compromiso moral de retribuir con su voto a quienes les dan "apoyos" y por otro lado, miedo por dejar de recibir bienes de primera necesidad.

\footnotetext{
${ }^{2}$ Corbetta, Pieregiorgio, Metodología y Técnicas de la Investigación Social, Trad. De Marta Díaz Ugarte, Madrid, Mc Graw Hill, 2007, p. 358.
} 
El compromiso que genera la entrega de dádivas y apoyos a las y los beneficiarios, tiene su contraparte en la obligación "de dar" en dinero o en especie por parte de candidatos, candidatas y gobernantes, obligación que hemos percibido llega a constituir el objetivo principal del gobierno. La población pide y solamente espera recibir.

\section{SITUACIÓN MARGINAL DEL MUNICIPIO DE CUETZALAN DEL PROGRESO}

Cuetzalan se encuentra en la parte noreste de Puebla enclavado en la Sierra Norte del estado, aislado geográficamente de los principales centros urbanos de la entidad federativa. Dentro del catálogo de localidades indígenas publicado por la Comisión Nacional para el Desarrollo de los Pueblos Indígenas CNDI (hoy Instituto Nacional de los Pueblos Indígenas), en el 2010 el municipio contaba con una población total de 47,433 personas de las cuales 38,926 se consideraban indígenas, es decir, el 82\%. En el mismo documento se cataloga como un municipio con grado muy alto de marginación. ${ }^{3}$ Por otro lado, de acuerdo a los indicadores socio económicos de la población total y la población indígena por municipio que publicó la CNDI en el año 2000, ${ }^{4}$ el 14.7\% de la población era analfabeta, mientras que un porcentaje similar hablaba únicamente alguna lengua indígena, en su mayoría el nahuat ${ }^{5}$ y los menos, totonaca. Cabe señalar que en ambos casos,

\footnotetext{
${ }^{3}$ Catálogo de localidades indígenas del ahora Instituto Nacional de los pueblos indígenas, elaborado con información del Censo de Población y Vivienda 2010 Comisión http:/www.cdi.gob.mx/localidades2010-gobmx/ consulta 16/05/2019

${ }^{4}$ Indicadores socioeconómicos de la población total y la población indígena por municipio, 2000 de la CNDI http://www.cdi.gob.mx/cedulas/2000/PUEB/21043-00. pdf consulta 16/05/2019

5 “ ... Al grupo dialectual central, náhuatl, pertenece a la lengua clásica que hablaban los aztecas. La lengua hablada en la Sierra Norte de Puebla, el náhuat, pertenece al grupo oriental. Allí se remplaza el fonema $/ t l /$ por $/ t /$, además de otras numerosas diferencias leicales y gramaticales...” Boucage, Pierre, Taller de Tradición Oral del CEPEC,
} 
el doble de mujeres que de hombres eran analfabetas y monolingües.

Ante este escenario de alto grado de marginalidad, aunado al analfabetismo y monolingüismo que obstaculizan el acceso a la información de la población, las comunidades de Cuetzalan constituyen tierra fértil para que se presente el "clientelismo", es decir, "el intercambio de bienes y servicios por apoyo político y votos. ${ }^{”}$ Como lo señala Santiago Nieto Castillo, "a mayor marginalidad social, mayor condicionamiento de programas sociales".7 Quien más necesidades vitales tiene, no se detiene a analizar propuestas electorales, ideologías políticas, ni perfiles de candidatos o candidatas, se conforma con recibir beneficios directos que les solucionen sus problemas inmediatos de supervivencia a cambio de su voto.

\section{EL TEJIDO COMUNITARIO SE VA DAÑANDO CON EL} SISTEMA POLÍTICO ELECTORAL ${ }^{8}$

Adicionalmente a la marginalidad, otro fenómeno que ha fomentado el clientelismo en el municipio es la llegada de los partidos políticos a las 8 juntas auxiliares que conforman el municipio: Reyesogpan de Hidalgo, San Andrés Tzicuilan, San Miguel Tzinacapan, Xiloxochico de Rafael Avila Camacho, Xocoyolo, Santiago Yancuitlalpan, Yohualichan

Cuerpo, cosmos y medio ambiente entre los nahuas de la Sierra Norte de Puebla. Una aventura en antropología, trad. De Elena Soldevila Duarte, México, UNAM, Plaza y Valdés Editores, 2012, p.26

${ }^{6}$ Schroter, Bárbara, "Clientelismo político: ¿existe el fantasma y cómo se viste? Revista mexicana de Sociología, México, 2010, vol.72, núm. 1, enero/marzo 2010, pp. 141175 http://www.scielo.org.mx/pdf/rms/v72n1/v72n1a5.pdf

7 Nieto Castillo, Santiago, Sin Filias ni fobias, memorias de un fiscal incómodo, México, Grijalbo, 2019, p. 99.

8 Entrevista con Saraí Rivadeneira, Radio Tzinaca, San Miguel Tzinacapan, Cuetzalan 11/04/18 
y Zacatipan. ${ }^{9}$ Anteriormente, los gobernantes comunitarios de las juntas auxiliares, se escogían a través de diferentes mecanismos de elección atendiendo a sus usos y costumbres. ${ }^{10}$ De cualquier manera su elección atendía a los méritos personales. Eran electos quienes se sabía habían trabajado en favor de la comunidad y destacado por su honradez y generosidad. Ya sea que hubieren ocupado cargos religiosos, como mayordomos, fiscales, topiles, tenientes de las danzas; cargos civiles comunitarios como regidores (de usos y costumbres, hacienda, educación, salud, etcétera) o bien cumplido de manera sobresaliente con las faenas ${ }^{11}$ correspondientes. Los partidos políticos están ejerciendo cada vez más su influencia, "llegaron los partidos y desgraciadamente nos han dividido hasta en familias ${ }^{12}$ \% . Los procesos de elección están siendo organizados por el Ayuntamiento mediante el uso de credenciales de elector e impresión de boletas donde figura el "candidato o candidata de la presidencia municipal”, quienes frecuentemente obtienen el triunfo gracias al acceso que tienen a los recursos. La idea de trabajo en favor de la comunidad se ha ido desdibujando y ha dado pie al clientelismo político. Ya no importa tanto la trayectoria de la persona, sino su capacidad de conseguir y repartir recursos directamente a la población.

9 Instituto Nacional para el Federalismo y Desarrollo Municipal http://www. inafed.gob.mx/work/enciclopedia/EMM21puebla/municipios/21043a.html consulta $18 / 05 / 2018$

${ }^{10}$ Las autoridades civiles se elegían popularmente mediante asambleas comunitarias, ya sea mediante votación a mano alzada, listones (la persona que sacaba el listón más largo obtenía el cargo) o mediante plebiscito (las y los electores se formaban detrás del candidato o candidata de su preferencia y obtenía el triunfo quien contara con un mayor número de personas formadas en su fina). Entrevista con Saraí Rivadeneira, Radio Tzinaca, San Miguel Tzinacapan, Cuetzalan 11/04/18

11 Trabajo que se hace de manera colectiva en beneficio de la comunidad.

12 Entrevista con Angélica Gutiérrez, Radiodifusora "La voz de la Sierra Norte" XECTZ 13/04/18 
Al respecto, Pilar Calveiro en su artículo "Repensar y ampliar la democracia. El caso del Municipio Autónomo de Cherán K’eri” señala: "La idea que prevalece en la comunidad es que los partidos no solo provocan divisiones innecesarias sino que, además, se vinculan de manera utilitaria y clientelar con su población, intentando cooptarlos mediante 'favores' o promesas de cargos. Se los percibe como entes externos, ajenos a su cultura, sobreimpuestos de manera artificiosa, utilitarios y, por lo mismo, prescindibles e incluso dañinos ${ }^{13}$ "

De igual manera, los partidos han llegado a las comunidades de Cuetzalan a romper con las formas tradicionales de proponer y elegir a sus autoridades civiles comunitarias, constituyen una amenaza a las formas indígenas de organización comunitaria tradicional. Corrompen a las personas y les imponen valores materiales alejados de los tradicionales comunitarios. Ante este escenario, existen grupos organizados en algunas de las comunidades del municipio que están trabajando en la manera de recuperar sus formas ancestrales de organización política.

\section{CUETZALAN, TIERRA FÉRTIL PARA EL REPARTO DE DÁDIVAS Y PROGRAMAS SOCIALES}

Es de llamar la atención el hecho de que la gente que se ve beneficiada con dádivas o programas sociales, retribuye efectivamente el apoyo al momento de sufragar, siendo que el voto es libre y secreto. La persona que acude a votar, en general lo hace de manera personalísima, con independencia, sin ser supervisada u observada y aún así, no vota libremente, lo hace condicionada. Del trabajo de campo llevado a cabo

${ }^{13}$ Calveiro, Pilar, "Repensar y ampliar la democracia. El caso del Municipio Autónomo de Cherán K’eri”, Argumentos, Universidad Autónoma Metropolitana unidad Xochimilco, México, 2014, vol 27, núm75, mayo-agosto 2014, pp. 193-212. 
en las comunidades de Cuetzalan, observamos dos fenómenos que tratan de dar una respuesta al comportamiento ante las urnas de las y los electores.

\section{COMPROMISO MORAL}

En primera instancia, existe un compromiso moral de la gente, un valor arraigado en su cultura. Las personas de las comunidades son "gente buena, noble" ${ }_{14}$ con un gran sentido de justicia y compromiso moral por trabajar en favor de la comunidad, situación difícil de comprender desde una visión eurocentrista, individualista. De acuerdo al "derecho comunitario" saben que tienen que actuar bien, de lo contrario hay repercusiones. Isauro Chávez, jefe de la radio comunitaria de Cuetzalan, define el derecho indígena, comunitario como:

"Saber diferenciar entre lo bueno y lo malo, el día y la noche, lo blanco de lo negro, hay que hacer el bien, no ofender, de lo contrario hay consecuencias, los entes sobrenaturales cobran vida y se puede revertir su enojo, al igual que pasa con la tierra. Dentro de la cosmovisión (de la Sierra Norte), la tierra está viva y ... cualquier cosa que le hagas, la estás dañando y es una afectación que se puede revertir”.Si les llegan a "regalar algo", las personas sienten la necesidad de retribuir el gesto mediante el voto. Difícilmente entienden que están siendo utilizadas y manipuladas, además de que se están usando recursos públicos para ello. ${ }^{15}$

${ }^{14}$ Entrevista con Saraí Rivadeneira, Radio Tzinaca, San Miguel Tzinacapan, Cuetzalan 11/04/18

${ }^{15}$ Entrevista con Isauro Chávez, Radiodifusora "La voz de la Sierra Norte” XECTZ 22/01/19 
Angélica Gutiérrez, también de la radio comunitaria, considera que la mayoría de los indígenas se sienten muy agradecidos y comprometidos, "si te regalan algo, tienes que corresponder con tu voto". Platica de una señora que no alcanzó playera en un evento de campaña, comentó que se sentía liberada del compromiso de votar por ese candidato. ${ }^{16} \mathrm{De}$ haber recibido playera, su voto estaría comprometido "moralmente". Seguramente no se hubiera sentido cómoda de votar por una o un candidato distinto a pesar de que nadie la observara y fuera ella la única testigo al depositar su voto en la urna.

Para Silvia Guerrero Molina, ex candidata independiente a la presidencia municipal apoyada por la Unión de Cooperativas Tosepan, el compromiso moral de votar en agradecimiento a los beneficios recibidos, "también es una cuestión de cultura, si yo te doy algo, tu vas a vivir eternamente agradecido conmigo... (por eso) no culpo a las comunidades, es parte de su ser" ${ }^{17}$

Se acerca el periodo electoral y la gente sabe que se verá beneficiada por un momento, y aún así, responde con su voto. Benita Lobato, además de locutora de la radio, atiende a las personas que acuden a la radiodifusora a solicitar algún tipo de asesoría o consejo y al respecto me platica que cuando le preguntan del tema, ella les contesta: “ ¿qué, se van a quedar con la torta y el boing 6 años?”"18 El beneficio es efímero y aún así lo reciben y retribuyen.

\footnotetext{
${ }^{16}$ Entrevista con Angélica Gutiérrez, Radiodifusora "La voz de la Sierra Norte" XECTZ 13/04/18

${ }^{17}$ Entrevista a Silvia Guerrero Molina, Cuetzalan, 22/01/19

${ }^{18}$ Entrevista con Benita Lobato, Radiodifusora "La voz de la Sierra Norte" XECTZ $13 / 04 / 18$
} 


\section{TEMOR A PERDER BENEFICIOS}

Adicionalmente al compromiso moral que adquieren las personas al recibir dádivas o ser beneficiarias de programas sociales, también prevalece la inquietud respecto a la posibilidad de perder los pocos beneficios que se pueden llegar a obtener si se vota por fórmulas contrarias a aquéllas que han abanderado los recursos. "Esta conducta, profundamente arraigada en nuestra nación, supone ... la generación de un temor real del ciudadano de escasos recursos, quien siente miedo de quedarse sin recursos para comer" ${ }^{19}$ Dicha inquietud tiene en gran medida su fundamento en las constantes amenazas que reciben las personas beneficiarias de los programas, por parte de quienes deciden y controlan el acceso a los recursos.

Sobre las asesoras del programa Prospera ${ }^{20}$ nos comenta muy molesta la maestra Chelito quien de manera voluntaria colabora en el levantamiento de censos para el nuevo padrón de personas beneficiarias de los programas sociales de la Secretaría de Bienestar. La maestra señala que manipulan y amenazan a la gente con quitarles el beneficio si se anotan en el nuevo censo. "Son tan perversas, va a desaparecer su programa y todavía le dicen a la gente que no ingrese a los nuevos programas", ${ }^{21} \mathrm{~A}$ pesar de que les explica que ese programa va a desaparecer, la gente prefiere no empadronarse de nuevo por temor. Cabe señalar "que existe

\footnotetext{
${ }^{19}$ Nieto Castillo, Santiago, op. cit., p. 98.

${ }^{20} \mathrm{El}$ programa de Inclusión Social PROSPERA tiene como objetivo contribuir a fortalecer el cumplimiento efectivo de los derechos sociales que potencien las capacidades de las personas en situación de pobreza, a través de acciones que amplíen sus capacidades en alimentación, salud y educación, y mejoren su acceso a otras dimensiones del bienestar. https:/datos.gob.mx/busca/organization/about/prospera consultado el 7/06/19

${ }^{21}$ Entrevista con María del Consuelo Valle Espinosa, Tosepan, Cuetzalan, 21/01/19
} 
un grado de vulnerabilidad de las propias vocales del programa, quienes seguramente reciben presión de los servidores públicos que las utilizan con tal de eludir la responsabilidad legal”. ${ }^{22}$

Rufina Villa, ex candidata a la presidencia municipal por Morena, también refiere las amenazas que recibieron algunas personas de que les fueran retiradas sus "láminas", entregadas como parte del programa "techo digno": 23 "Si ustedes votan por otro partido, vamos a venir a bajar las láminas, tienen que votar por el PRI, ya no queremos al PAN, pero esta vez le toca al PRI". Agrega Rufina que "se ha jugado mucho con la pobreza y la desinformación”. ${ }^{24}$

$\mathrm{Al}$ respecto, como parte de la aplicación de encuestas el día de la jornada electoral, una señora manifestó que vota desde que es beneficiaria de Prospera, lo que supone una retribución en agradecimiento y tal vez temor a perder el beneficio. Así mismo, las personas beneficiarias del programa "cuartos rosas", que en Cuetzalan se llamó "cuartos azules", 25 fueron amenazadas con no recibir la llave del cuarto si no votaban por el partido "benefactor". Como estos, hemos recopilado varios testimonios que ejemplifican las amenazas y manipulación electoral de que son sujetas las personas del municipio.

22 Nieto Castillo, Santiago, op. cit, p. 100.

${ }^{23}$ A través del programa Vivienda Digna del FONHAPO, el gobierno federal otorga subsidios a los hogares mexicanos en situación de pobreza con ingresos por debajo de la línea de bienestar, con carencia de calidad y espacios de la vivienda, para que construyan, amplíen o mejoren sus viviendas. https://www.gob.mx/fonhapo/acciones-yprogramas/programa-vivienda-digna consultado el 7/06/19

${ }^{24}$ Entrevista con Rufina E. Villa Hernández, Hotel Taselotzin, Cuetzalan, 22/01/19

${ }^{25} \mathrm{El}$ programa de los cuartos rosas de la Secretaría de Desarrollo Agrario, Territorial y Urbano (SEDATU), que en Cuetzalan se llamó cuartos azules debido a que estaba el Partido Acción Nacional al frente del municipio, tiene como objetivo proveer a las familias de un cuarto adicional para evitar el hacinamiento y con ello la violencia de género en contra de las niñas y las mujeres. En la junta auxiliar de Zacatipan, Cuetzalan se observaron varios cuartos distribuidos por la carretera de manera aislada que en su mayoría estaban abandonados. Aproximadamente se detectaron 8, de los cuales únicamente uno estaba habitado. 
Vine a colación lo que a nivel federal, el licenciado Andrés Manuel López Obrador, como parte de un discurso de campaña señaló:

"Voto parejo. Y cuando lleguen los mañosos allí a entregar el dinero ...

Compran los votos por 500 pesos, mil pesos, dos mil pesos; entregan despensas ... láminas ... tinacos... marranos: eso es lo que son, sinvergüenzas corruptos. Si están muy necesitados, agarren, agarren. Está permitido ... decir una mentira piadosa, cuando lleguen los corruptos (...) "vas a tener tu block, tu saco de cemento, tu despensa, ¿pero vas a votar por nosotros?”... sí, y a la hora de la hora "toma tu voto". ¡ Voto libre y secreto!" ${ }^{26}$

A pesar de ser el común denominador, esta situación está empezando a ser visibilizada y rechazada en algunos espacios. Angélica Gutiérrez hace referencia al trabajo que han hecho las radios al "fortalecer la idea de que no te regalan y que hay que denunciar cuando se condiciona el voto”, así como también han hecho énfasis en que solamente "tú debes decidir por quien votar" embargo, es complicado cambiar una dinámica cultural que de alguna manera ha funcionado para ambas partes y sobretodo la idea de las personas de tener que retribuir los beneficios recibidos, como un compromiso moral.

\section{OBLIGACIÓN “DE DAR” COMO VALOR ENTENDIDO}

Ha llegado a tal grado la expectativa por recibir recursos durante el periodo electoral, que las personas de las comunidades ya no esperan a que las visiten, directamente acuden a las y los candidatos a solicitar los apoyos. ${ }^{28}$

${ }^{26}$ Extracto del discurso pronunciado en campaña por Andrés Manuel López Obrador, candidato por la Coalición Juntos Haremos Historia a la Presidencia de la República, Atlacomulco, Edo. De México, 28/05/2018

${ }^{27}$ Entrevista con Angélica Gutiérrez, Radiiodifusora "La voz de la Sierra Norte" XECTZ 13/04/18

${ }^{28}$ Saraí, de la "Radio Tzinaca" comentaba: También hemos caído mucho en este pueblo en que ya no tienen que venir a ofrecerte; la gente va directamente a ver al 
Tienen la creencia de que la obligación de quienes pretenden obtener un cargo es precisamente ayudar con dinero o en especie directamente a quienes lo necesiten.

Invitan a candidatos, candidatas y/o diferentes autoridades a ser madrinas o padrinos de bodas, bautizos, presentaciones, generaciones escolares, ya que de antemano saben que tendrán un beneficio mutuo. Así, platica Saraí que los alumnos de la escuela de San Miguel Tzinacapan, fueron a invitar a un candidato como padrino de generación, "vino a lucirse, regaló una tablet que no funcionó” ${ }^{29}$

En este mismo sentido, Silvia Guerrero platica que todas las mañanas, durante el tiempo que duró su campaña, se presentaban personas directamente en su casa a solicitar diferentes apoyos; "necesito para medicamentos, ... necesito para la escuela, y pues aunque tu decías: no voy a dar apoyos, al final de alguna manera tenías que ser sensible a la necesidad de quien se acercaba y en algunos casos sí tuvimos que apoyar”30

$\mathrm{Al}$ ser una candidatura independiente casi no recibieron financiamiento por parte de las autoridades electorales, por el contrario tuvieron que poner de sus bolsas. De cualquier manera, Silvia y su equipo pretendieron hacer una campaña diferente, intentaron recuperar procesos comunitarios ancestrales. Para ello, elaboraron un diagnóstico sobre las necesidades de las comunidades con información que iban recopilando en sus diferentes visitas y reuniones con la gente (como ejemplo, formó parte del diagnóstico la inquietud de una comunidad que tiene desde hace varios años un terreno para construir su panteón, pero no han logrado obtener la autorización del municipio).

candidato para solicitarle apoyo para las fiestas patronales"

29 Entrevista con Saraí Rivadeneira, Radio Tzinaca, San Miguel Tzinacapan, Cuetzalan 11/04/18

${ }^{30}$ Entrevista a Silvia Guerrero Molina, Cuetzalan, 22/01/19 
A partir de ese diagnóstico, plantearon sus propuestas de campaña. Explicaban en las comunidades los beneficios que tendrían al ver satisfechas sus necesidades, aún así "a la gente no se le quita todavía ese sentimiento de que va a venir el candidato y hay que pedirle". ${ }^{31} \mathrm{Al}$ final, a pesar de las buenas ideas y del acercamiento a las comunidades, la fórmula quedó en cuarto lugar, quienes lograron el primero y segundo, tuvieron recursos y programas que repartir para comprometer el voto. No fue fácil intentar cambiar la mentalidad de la gente ya que constituye “... una práctica cultural de muchos años de que va a venir el candidato (y) hay que hacer una solicitud para algo" ${ }^{32}$

La necesidad extrema de las personas es aprovechada por quienes ostentan el poder para obtener votos y mantenerse en él. Esta situación constituye un círculo vicioso: si tengo recursos para repartir, puedo comprar votos que me llevan al poder y ese poder me da recursos para seguir repartiendo.

\section{VI. “EL QUE PAGA PARA LLEGAR, LLEGA PARA ROBAR”. 33 EL CLIENTELISMO COMO VIOLACIÓN DE DERECHOS}

En el imaginario colectivo de las comunidades, un buen gobernante es quien les da, ya sea en dinero o en especie, o bien quien, valiéndose de recursos públicos, reparte a discreción programas sociales: becas, techos de lámina, cuartos, útiles escolares y demás materiales. Desafortunadamente la situación tan precaria en que viven las personas, es aprovechada por quienes tienen los recursos, públicos o privados, para

\footnotetext{
${ }^{31}$ Idem

32 Idem

${ }^{33}$ Lema presentado en la campaña electoral de la candidata independiente Silvia Guerrero Molina, impulsada por la Unión de Cooperativas Tosepan a la presidencia municipal de Cuetzalan en 2018.
} 
comprar votos, lo que se ha naturalizado como una obligación a cargo del gobierno o de quien pretenda llegar al poder, de dar y beneficiar de manera directa.

Estas prácticas constituyen manifestaciones de violencia política, lo que se traduce en violaciones a los derechos humanos, tanto sociales como individuales, atentados a la democracia, así como también en conductas constitutivas de delitos electorales sancionadas por la ley de la materia. ${ }^{34}$

Los programas sociales, siguiendo a Santiago Nieto, "son mecanismos institucionales diseñados para satisfacer derechos fundamentales de índole social” ${ }_{35}$ que el estado pone en marcha precisamente para cumplir con sus obligaciones derivadas tanto de instrumentos internacionales, ${ }^{36}$ como de la Constitución Política de los Estados Unidos Mexicanos. Es decir su implementación constituye la materialización, por parte del estado, de los derechos sociales. Al condicionar su otorgamiento a cambio de apoyo político electoral, concretamente a cambio de votos, se está desvirtuando su objetivo y con ello, vulnerando el derecho humano a la protección social para casos de necesidad.

${ }^{34}$ Ley General de Delitos Electorales, publicada en el Diario oficial de la Federación el 23 de mayo de 2014, Última reforma publicada el 19 de enero de 2018

${ }^{35}$ Nieto Castillo, Santiago, op cit. P 97

${ }^{36}$ Pacto Internacional de Derechos Económicos, Sociales y Culturales, adoptado en Nueva York el 16 de diciembre de 1966, firmado por México el 23 de marzo de 1981 y publicado en el Diario oficial de la Federación el 12 de mayo del mismo año; La Convención Americana sobre Derechos Humanos, adoptada en San José, Costa Rica, el 22 de noviembre de 1969, firmado por México el 2 de marzo de 1981 y publicado en el Diario oficial de la Federación el 7 de mayo del mismo año; Protocolo Adicional de la Convención Americana sobre Derechos Humanos "Protocolo de San Salvador", adoptado en San Salvador el 17 de noviembre de 1988, firmado por México en la misma fecha y publicado en el Diario Oficial de la Federación el $1^{\circ}$ de septiembre de 1998 
El derecho individual a participar en la vida política del estado mexicano, se concreta a través del ejercicio de los derechos político electorales, reconocido, tanto en tratados internacionales, ${ }^{37}$ como en la Constitución. El artículo 35 constitucional reconoce el derecho que tiene la ciudadanía a votar y a ser votada. Más adelante, la fracción I del artículo 41, establece que el sufragio deberá ser universal, libre, secreto y directo. De esta manera, la manipulación de las y los electores para votar en un sentido determinado a cambio de prebendas, arrebata libertad y secrecía al ejercicio electoral lo que constituye una violación al derecho humano de participar en la vida política de la nación, así como un atentado contra la "libre expresión de la voluntad de los electores". ${ }^{38}$

$\mathrm{Al}$ respecto la Comisión de Derechos Humanos de la Organización de las Naciones Unidas, en su recomendación general número 25 referente a la participación en los asuntos públicos y el derecho al voto, señala:

"Las personas con derecho de voto deben ser libres de votar a favor de cualquier candidato y a favor o en contra de cualquier propuesta que se someta a referéndum o plebiscito, y de apoyar al gobierno u oponerse a él, sin influencia ni coacción indebida de ningún tipo que pueda desvirtuar o inhibir la libre expresión de la voluntad de los electores. Estos deberán poder formarse una opinión de manera independiente, libres de toda violencia, amenaza de violencia, presión o manipulación de cualquier tipo”. ${ }^{39}$

${ }^{37}$ Pacto Internacional de los Derechos Civiles y Políticos, adoptado en Nueva York el 16 de diciembre de 1966, firmado por México el 23 de marzo de 1981 y publicado en el Diario oficial de la Federación el 20 de mayo del mismo año y La Convención Americana sobre Derechos Humanos, op cit,

${ }^{38}$ Pacto Internacional de los Derechos Civiles y Políticos, op cit.

39 Observación general N.o 25 del Comité de Derechos Humanos de la ONU, 57 periodo de sesiones, 1996, https://conf-dts1.unog.ch/1\%20SPA/Tradutek/Derechos_ hum_Base/CCPR/00_2_obs_grales_Cte\%20DerHum\%20\%5BCCPR\%5D. html\#GEN25 consultado el 10/06/19 
En este mismo orden de ideas, la manipulación de que es víctima la ciudadanía para votar en una dirección determinada por una opción ajena a su voluntad, también constituye un golpe a la vida democrática y soberana del país. Democracia, entendida como "un sistema de vida fundado en el constante mejoramiento económico, social y cultural del pueblo" ${ }^{40}$ e "indispensable para la estabilidad, la paz y el desarrollo de la nación.” ${ }_{41}$ Por otro lado, al no reflejar de manera genuina las preferencias ideológicas del electorado, difícilmente se puede hablar de que la soberanía de la nación reside en el pueblo, como lo mandata el artículo 39 constitucional.

Las conductas anti democráticas y violatorias de derechos humanos antes descritas, también son constitutivas de delitos electorales, entendidos como "acciones u omisiones que lesionan o ponen en peligro el adecuado desarrollo de la función electoral y atentan contra las características del voto que debe ser universal, libre, directo, personal e intransferible" ${ }_{42} \mathrm{De}$ esta manera, la ley de la materia tipifica dichas conductas, ya sea que se cometan por servidores públicos, o no y establece sanciones aplicables a quienes las ejecuten.

El Instituto Nacional de Ciencias Penales, en conjunto con la Fiscalía Especializada para la Atención de Delitos Electorales, ha elaborado una clasificación sobre los diez delitos electorales que se deben conocer y denunciar. ${ }^{43}$ De éstos, dos corresponden a la manipulación del voto a

${ }^{40}$ Artículo $3^{\circ}$, fracción II, apartado a) de la Constitución Política de los Estados Unidos Mexicanos.

${ }^{41}$ Carta Democrática Interamericana, firmada en Lima, Perú el 11 de septiembre del 2001

${ }^{42}$ Ley General en Materia de Delitos Electorales, publicada en el Diario Oficial de la Federación el 23 de mayo de 2014, última reforma publicada el 19 de enero de 2018

43 "Diez delitos electorales que debemos conocer y denunciar", INACIPE, FEPADE, Ciudad de México, 2018, http://www.inacipe.gob.mx/inicio/ documentos/10Delitoselectorales.pdf, consultado el 9 de junio de 2019 
cambio de condicionamiento de programas sociales, o bien a la entrega de prebendas.

Utilizar bienes o servicios públicos en una campaña, constituye una conducta delictiva que se comete por una o un servidor público que destina bienes (públicos) para apoyar a una candidatura o bien para perjudicar a algún candidato o candidata, lo que se sanciona con hasta 400 días de salario mínimo y prisión de dos a nueve años.

Se sanciona de la misma manera al servidor o servidora pública que condicione o restrinja el acceso a servicios públicos, programas sociales, otorgamiento de concesiones, permisos, licencias o la realización de obras públicas por cuestiones electorales.

Asimismo, se tipifican como delitos y se castigan con hasta 100 días de salario y de 6 meses a 3 años de prisión, conductas llevadas a cabo por quienes soliciten "votos por paga, promesa de dinero u otra contraprestación, o bien mediante violencia o amenaza, presione a otro a asistir a eventos proselitistas, o a votar o abstenerse de votar por un candidato, partido político o coalición, durante la campaña electoral, el día de la jornada electoral o en los tres días previos a la misma. En el mismo artículo se contempla un aumento en la pena si la persona responsable es integrante de un organismo de seguridad púbica. De igual manera se establecen sanciones aplicables a quienes amenacen con suspender beneficios de programas sociales o bien soliciten evidencia del sentido del voto, lo que constituye una violación a la secrecía del sufragio. 


\section{CONCLUSIÓ N}

Ante las necesidades y carencias que tiene la población, el municipio de Cuetzalan ha sido tierra fértil para el reparto de dádivas y condicionamiento de programas sociales, mediante la inclusión de un sistema de partidos que cada vez está rompiendo más el tejido social y desvirtuando los valores comunitarios ancestrales que han mantenido la armonía y cohesión social.

Debido al compromiso moral a que se sienten sujetas las personas que reciben todo tipo de beneficios, aunado al miedo de perderlos, es complicado tanto informar y sensibilizar a las personas a cerca de sus derechos político electorales, como hacer conciencia de que el voto es libre y secreto y de que nadie tiene derecho a interferir en esa decisión personalísima.

Adicionalmente, es fundamental visibilizar que dichas conductas son contrarias a los derechos humanos, atentan en contra de la democracia del estado e inclusive, constituyen delitos que deben ser denunciados y castigados. Esto último, para mandar un mensaje de rechazo, tanto a las personas que reparten, como a las que reciben.

Por último, recuperar valores comunitarios en que se fortalezca la idea de que quien trabaja en favor de la comunidad, pone el buen ejemplo, actúa con honradez y respeto, es quien merece estar al frente del gobierno ya que de antemano se sabe tomará las decisiones que más beneficien a la comunidad y no quien reparta una torta y un boing que de antemano se sabe, no duran 6 años. 


\section{FUENTES}

\section{BIBLIOGRAFIA}

Boucage, Pierre, Taller de Tradición Oral del CEPEC, Cuerpo, cosmos y medio ambiente entre los nahuas de la Sierra Norte de Puebla. Una aventura en antropología, trad. De Elena Soldevila Duarte, México D.F., UNAM, Plaza y Valdés Editores, 2012.

Calveiro, Pilar, "Repensar y ampliar la democracia. El caso del Municipio Autónomo de Cherán K’eri”, Argumentos, Universidad Autónoma Metropolitana unidad Xochimilco, México D.F., 2014, vol 27, núm75, mayo-agosto 2014.

Conbetta, Pieregiorgio, Metodología y Técnicas de la Investigación Social, Trad. De Marta Díaz Ugarte, Madrid, Mc Graw Hill, 2007.

"Diez delitos electorales que debemos conocer y denunciar", INACIPE, FEPADE, Ciudad de México, 2018, http://www.inacipe.gob.mx/inicio/ documentos/10Delitoselectorales.pdf, consultado el 9 de junio de 2019.

Nieto Castillo, Santiago, Sin Filias ni fobias, memorias de un fiscal incómodo, Ciudad de México, Grijalbo, 2019.

Schroter, Bárbara, "Clientelismo político: ¿existe el fantasma y cómo se viste? Revista mexicana de Sociología, México D.F., 2010, vol.72, núm. 1, enero/ marzo 2010. http://www.scielo.org.mx/pdf/rms/v72n1/v72n1a5.pdf

\section{ENTREVISTAS}

Angélica Gutiérrez, Radiodifusora “La voz de la Sierra Norte” XECTZ 13/04/18 Benita Lobato, Radiodifusora "La voz de la Sierra Norte” XECTZ 13/04/18 Isauro Chávez, Radiodifusora "La voz de la Sierra Norte” XECTZ 22/01/19 María del Consuelo Valle Espinosa, Tosepan, Cuetzalan, 21/01/19 
Rufina E. Villa Hernández, Hotel Taselotzin, Cuetzalan, 22/01/19

Saraí Rivadeneira, Radio Tzinaca, San Miguel Tzinacapan, Cuetzalan 11/04/18

Silvia Guerrero Molina, Cuetzalan, 22/01/19

\section{PÁGINAS ELECTRÓNICAS}

Instituto Nacional para el Federalismo y Desarrollo Municipal

http://www.inafed.gob.mx/work/enciclopedia/EMM21 puebla/ municipios/21043a.html,consulta 18/05/2018

Programa de inclusión social Prospera https://datos.gob.mx/busca/organization/ about/prospera consultado el 7/06/19

Programa Vivienda Digna https:/www.gob.mx/fonhapo/acciones-y-programas/ programa-vivienda-digna consultado el 7/06/19

Catálogo de localidades indígenas del ahora Instituto Nacional de los pueblos indígenas, elaborado con información del Censo de Población y Vivienda 2010 Comisión http://www.cdi.gob.mx/localidades2010-gobmx/ consulta $16 / 05 / 2019$

Indicadores socioeconómicos de la población total y la población indígena por municipio, 2000 de la CNDI http:/www.cdi.gob.mx/cedulas/2000/ PUEB/21043-00.pdf consulta 16/05/2019

Observación general N. 25 del Comité de Derechos Humanos de la ONU, 57 periodo de sesiones, 1996, https://conf-dts1.unog.ch/1\%20SPA/ Tradutek/Derechos_hum_Base/CCPR/00_2_obs_grales_Cte\%20 DerHum\%20\%5BCCPR\%5D.html\#GEN25 consultado el 10/06/19 